López, R. and Barragán, J. (2008). "Equivalent Roughness of Gravel-Bed Rivers." J. Hydraul. Eng., 134(6), 847-851. http://dx.doi.org/10.1061/(ASCE)0733-9429(2008)134:6(847)

(c) 2008 ASCE

\title{
Equivalent roughness of gravel-bed rivers
}

\author{
Raúl López ${ }^{1}$ and Javier Barragán²
}

\begin{abstract}
${ }^{1}$ Associate Professor, Dept. of Agroforestry Engineering, Univ. of Lleida, Av. Alcalde Rovira Roure 191, E25198 Lleida, Spain (corresponding author). E-mail: rlopez@eagrof.udl.es

${ }^{2}$ Full Professor, Dept. of Agroforestry Engineering, Univ. of Lleida, Av. Alcalde Rovira Roure 191, E25198 Lleida, Spain
\end{abstract}

\begin{abstract}
The relation between the equivalent roughness and different grain size percentiles of the sediment in gravel-bed rivers was determined under the hypothesis that the vertical distribution of the flow velocity follows a logarithmic law. A set of 954 data points was selected from rivers with gravel size sediment or larger, with a non-sinuous alignment and free of vegetation or obstacles. According to the results, the $k_{s}$ roughness is equivalent to approximately $2.4 D_{90}, 2.8 D_{84}$, and $6.1 D_{50}$. No correlation was detected between the sediment sorting and the sediment mobility index on one hand, and, on the other, the coefficient of proportionality of each grain size percentile.
\end{abstract}

CE Database subject headings: Bed roughness; Flow resistance; Gravel; Mountain streams; Fluvial hydraulics. 


\section{Introduction}

Let us take a channel formed of granular particles along which there is a turbulent and hydraulically rough flow of a much greater depth than the size of these particles. If it is accepted that the vertical profile of velocity is logarithmic, the channel is wide, $z_{0}=k_{s} / 33$

and that $\kappa=0.40$, a Keulegan-type equation can be obtained

$$
\frac{V}{v_{*}}=5.76 \log \left(\frac{12.14 y}{k_{s}}\right)
$$

where $z_{0}=$ hydraulic roughness of the boundary; $k_{s}=$ equivalent roughness; $\kappa=$ von

Karman coefficient; $V=$ cross-section mean velocity; $v_{*}=$ shear velocity; and $y=$ mean

flow depth. Moreover, if uniform flow is considered, the shear velocity can be estimated as $v_{*}=\sqrt{g R S}$, where $g=$ gravitational acceleration; $R=$ hydraulic radius; and $S=$ bed slope. Eq. (1) can be used to predict flow resistance, given that it relates the mean flow velocity to the hydraulic geometry, and can moreover be related to uniform flow formulas such as those by Darcy-Weisbach or Manning.

The equivalent roughness is conventionally related to a characteristic size of the boundary material. It was observed that the $k_{s}$ value corresponding to a bed made up of a single layer of uniform sand is on the order of the size of the grains that make up this layer. Owing to the uniformity of grain size and their regular distribution in the bed, it is presumable that the roughness of the granular surface thus generated will be minimal. 
The estimation of $k_{s}$ through the procedure presented can be expressed as $k_{s}=\alpha_{i} D_{i}$, where $\alpha_{i}=$ coefficient of proportionality; $D_{i}=$ characteristic particle-size of the sediment; and $i=$ percentage of sediment of a smaller size. This coefficient of proportionality should tend towards values close to 1.0 for a boundary of uniform sediment. When this procedure is applied to gravel-bed rivers, $D_{i}$ is habitually taken as a percentile of the cumulative particle-size distribution corresponding to the intermediate axis of the particle.

Table 1 shows a selection of the values of the $\alpha_{i}$ coefficient in gravel-bed rivers found by different researchers through the regression of Keulegan-type equations. Despite the variation of the value of $\alpha_{i}$ that can be seen in Table 1 , for practical purposes a single value of $\alpha_{i}$ is usually adopted for each characteristic particle-size.

Table 1 shows that $\alpha_{i}$ reaches values significantly higher than 1.0, with various causes having been indicated by different authors as responsible for this. The heterogeneity of the sediment must be emphasized (both the size and shape of the particles as well as their disposition), the micro-topography, and the bedforms (both at a small and large scale), as well as the sediment bed load transport.

With regard to the first cause mentioned, it must be kept in mind that in granular beds made up of a single layer on a flat surface each elevation of the bed is directly related to the grain size, so the bed roughness can be satisfactorily expressed through the size of the particle. In contrast, in beds with multiple layers the superficial particles are lodged 
in hollows formed by underlying particles. In natural beds, with a mixture of particles sizes, the hollows formed are of different dimensions and a specific characteristic grain diameter $\left(D_{i}\right)$ will be less representative of the bed surface protuberances than in the case of a single layer bed (Smart et al. 2002).

On the other hand, adopting a single value of $\alpha_{i}$ for each grain-size percentile as a predictor of the flow resistance in coarse-grained rivers (of gravel, cobble, and boulder size) means considering that the effect of a whole series of sediment properties (such as the shape of the grain-size distribution curve, the arrangement of the particles, their shape and orientation, the packing, spatial distribution and sorting, particle cluster, etc.) remains unaltered in all channels and for any flow level. Essentially, the above is not true and the effect of the properties described can vary between different channels or from one point to another in the same channel reach and for different flows. This would contribute to explaining the variability of $\alpha_{i}$ that appears for each percentile in Table 1.

However, if the effect of the most influential properties of the sediment had a narrow range of variation, the consideration of an average value of $\alpha_{i}$ could be an adequate prediction tool. For example, in accordance with Bathurst (1982), the sediment sorting in gravel-bed rivers varies in a sufficiently narrow range (generally, $D_{84} / D_{50}$ is between 1.6 and 2.8) so that the effect of the size distribution can be assumed as roughly constant. Millar (1999) found no correlation between $D_{84} / D_{50}$ and $\alpha_{50}$ using a set of 176 data from 
gravel-bed rivers, so he maintained that sediment sorting has no significant effect on the observed bed roughness. The above-mentioned author attributed the increase in the value of $\alpha_{i}$, above the value of 1.0, to the form roughness, including in this the effect of particle protuberance or large-scale bedforms (e.g., sequences of pool-riffle), and particle clustering.

As for the effect of the sediment bed load, Whiting and Dietrich (1990) proposed a model for poorly sorted gravel beds with non-intense transport $\left(\tau / \tau_{c} \leq 2.0\right.$, where $\tau=$ shear stress; and $\tau_{c}=$ critical shear stress) in which the largest particles, static or moving at a much lower velocity than the flow, determine the resistance. The energy dissipation caused by the grains in saltation would be comparatively much lower, as long as their trajectory does not exceed the extent of the protuberances of the largest particles in the bed. On the other hand, a second group of researchers in laboratory flumes (e.g., Song et al. 1998) did detect an increase in roughness depending on the magnitude of the bed load transport in plane gravel bed conditions in which sediment sorting is comparatively more uniform than in natural beds.

If we accept the approximation $k_{s}=\alpha_{i} D_{i}$, Eq. (1) can be written as

$$
\frac{V}{v_{*}}=5.76 \log \left(\frac{12.14 y}{\alpha_{i} D_{i}}\right)
$$

This study is designed to determine the value of the coefficient of proportionality $\left(\alpha_{i}\right)$ in rivers with beds made of gravel, cobbles, and boulder sized particles for various 
characteristic sediment diameters $\left(D_{50}, D_{84}\right.$, and $\left.D_{90}\right)$ when Eq. $(2)$ is imposed, and to compare this value with those obtained by other authors. The aim is a substantial increase in the reliability of the predictive power of the equivalent roughness (and thus the flow resistance through Eq. (2)) in coarse material bed rivers, with regard to the relationships presented in Table 1. The aim is to reach this objective through a substantial increase in the database size widening of the hydraulic and geomorphologic interval in the context of gravel-bed rivers and mountain streams.

\section{Material and Methods}

To meet the aims of this study, a set of hydrometric data was compiled from rivers whose beds are made up of sediment particles of gravel size or larger, through a selection of those found in the literature. Data were also incorporated from our own research carried out in rivers in the Spanish Pyrenees (López, 2005). All the data included had to correspond to straight reaches of channel, non-vegetated, and free of obstacles, with a steady and macroscopically uniform flow. These requirements minimized the effects of vegetation and changes in channel shape (cross section, slope, and alignment) on flow resistance. However, it must be taken into account that, owing to the channel morphology of mountain and gravel-bed rivers and their low relative submergence conditions, in reality, the flow is varied on a detailed scale. Thus, the requirement of uniformity must be understood as the mean along the reach, considering the equality between the bed, water 
surface, and friction slopes to be sufficient at a macroscopic scale (or, failing that, the equality of the first two or if the authors stated that the flow in the reach was uniform or quasi-uniform). Moreover, the $D_{50}$ value had to be equal to or higher than $2 \mathrm{~mm}$, which corresponds to gravel, cobble, or boulder-bed rivers. Similarly, the flow had to be turbulent and hydraulically rough and the ratio of the free surface width to mean depth $(T / y)$ had to be above a threshold of approximately 10, with the aim of ensuring that the flow in the central zone of the section was not influenced by the channel banks.

Various bibliographic sources consulted provide data for different reaches for which, in turn, data have been obtained for different discharges. Despite meeting the requisites imposed, anomalous behavior has been observed on occasions in all or part of the data for a reach (e.g., outliers or an abnormal trend of flow resistance with relative submergence). In this case, it was decided to adopt the criteria of rejecting all the data from the reach in question, but still accept data obtained in other valid reaches in the same source. After applying the selection requirements referred to above, a set of 954 data were compiled from over 400 reaches of gravel-bed rivers from different world regions. This set corresponds to 25 bibliographic references from the 1955-2002 period and also 16 data derived from our own measurements in the Pyrenees (see Table 2).

The database compiled is among the largest that has ever been used to determine the equivalent roughness of gravel-bed rivers. Moreover, the selected set was 
representative of a wide geomorphologic and hydraulic range. For example, the $S$ values ranged between $0.001 \%$ and $16 \%$ (mean $=1.1 \%$; coefficient of variation $\mathrm{COV}=147 \%)$; $D_{50}$ varied between $7 \mathrm{~mm}$ and $0.5 \mathrm{~m}($ mean $=0.12 \mathrm{~m} ; \mathrm{COV}=84 \%)$ and $y / D_{50}$ between 0.23 and $283($ mean $=17.6 ; \mathrm{COV}=177 \%)$. If the size and variety of the database compiled is taken into account, the number of sources consulted, the period these cover and the measurement conditions in mountain rivers, it is impossible to guarantee rigorous uniformity in either the measurement procedures or the uniform quality of the data. However, the type of variables measured (mean flow velocity or discharge, depth, longitude, and grain size) and the similarity of the methods used, means that there is considered to be a high enough degree of uniformity for the aims proposed.

Given that the $V, v^{*}, y, D_{50}, D_{84}$, and $D_{90}$ values were known for each of the data, the only unknown in Eq. (2) was $\alpha_{i}$. The value of $\alpha_{i}$ was calculated through the leastsquare regression of Eq. (2) for all the selected data, taking $y / D_{i}$ as an independent variable and $V / v *$ as a dependent variable. Consequently, a value of $\alpha_{i}$ was obtained for each of the three characteristic grain sizes studied. However, it must be pointed out that the same percentiles were not available for all the data. Consequently, the size of the data set was different for each percentile, being made up of 875 for $D_{50}, 762$ for $D_{84}$ and 535 for $D_{90}$. 


\section{Results and Discussion}

Table 3 presents the value for $\alpha_{i}$ calculated for each grain-size percentile considered together with the value of the mean standard error (MSE) and the coefficient of determination for regression $\left(r^{2}\right)$, calculated with respect to the dependent variable of Eq. (2). The results obtained are within the range of variation found in the literature studied (Table 1), except the value of $\alpha_{90}$, which is lower than the two referred. Table 3 shows that the worst result is shown by $D_{50}$. However, as the difference with the results of the other percentiles is very small and, moreover, the fact that the set of data for the three percentiles is not the same, it is not possible to recommend categorically the use of one percentile rather than the others.

With the aim of detecting the influence of the heterogeneity of the particle size on the variability of $\alpha_{i}$, the relation between the sediment sorting index (expressed as $D_{84} / D_{50}$ ) and the value of $\alpha_{90}$ (obtained by solving Eq. (2) for each of the data) has been represented in Fig. 1. Only 520 points appear in Fig. 1, this being the number of data for which the value of the three percentiles was known. In any case, Fig. 1 shows that the sorting index considered does not explain the variance of $\alpha_{90}$. This coincides with the findings by Millar (1999). The same behavior was observed for the correlation of $\alpha_{84}$ or $\alpha_{50}$.

In accordance with the model described by Whiting and Detrich (1990), given that the vast majority of the selected data showed a value of the sediment mobility index 
$\left(\tau / \tau_{c}\right)$ less than 2 or 3 (98\% less than 2 and $88 \%$ less than 1$)$ and corresponded to poorly sorted beds (Fig. 1), it would be expected that the effect of the bedload transport on $\alpha_{i}$ would be negligible. The above is confirmed by the lack of explanatory power of the correlation between $\alpha_{i}$ and $\tau / \tau_{c}\left(r^{2}<0.1\right.$ for $\alpha_{50}$ and $r^{2}<0.2$ for $\left.\alpha_{90}\right)$, taking $\tau=\gamma R S$ (where $\gamma=$ specific weight of water) and $\tau_{c}=0.029\left(\gamma_{s}-\gamma\right) D_{84}$ (Ackers and White 1973) (where $\gamma_{s}=$ specific weight of particle).

Given the result of the analysis of correlation presented above, the variability detected in the equivalent roughness could be attributed to various factors that are presented below. In first place, the contribution of measurement errors to the scatter observed must not be forgotten and to the different degrees of deviation with regard to the hypothesis of uniform flow and prismatic channel. Moreover, it must be kept in mind that there are problems related to measurement and the definition of the cross-section in poorly sorted beds and under low relative submergence conditions, because the profile of the roughness elements is uneven or emerges in different segments (Bathurst 1985, Smart et al. 2002), problems that have generally not received a uniform treatment.

Furthermore, the effect of the characteristic bedforms of gravel beds must be emphasized, on both a small scale (e.g., particle cluster) and a large scale (pool-riffle or step-pool sequences). However, the different methods proposed to separate the grain and form components in gravel-bed rivers show serious limitations (e.g., in relation to the 
criteria adopted to determine the grain component, whether or not the form component varies with flow relative submergence or the difficulty of treating bedforms such as pebble clusters) that in practice hinder their application for prediction purposes (Millar 1999).

Similarly, other properties of the sediment that could not be analyzed owing to lack of information (shape, disposition, orientation, etc.) could also have contributed to the scatter of the values of $\alpha_{i}$. To an extent, this dispersion could also be attributed to the effect of the deviations that can appear in the relation between $z_{0}$ and $k_{s}$ or in the value of the von Karman coefficient, with respect to the values adopted.

Also, it is necessary to take into account the effect that the data with low relative submergence can have on the value of $\alpha_{i}$, caused by the fact that, in these cases, the validity of the logarithmic law of velocity distribution is questionable. The analysis of the effect on the determination of $\alpha_{i}$ of the division of the database in function of the relative submergence could throw some light on this. As a preliminary step, and awaiting a more exhaustive analysis that could be undertaken in future works, the value of $r^{2}$ (imposing $\alpha_{84}=2.80$ (Table 3 )) was calculated for the two subsets determined by taking $y / D_{84}=4$ (Bathurst 1985) as a division threshold. For $y / D_{84}<4(N=485)$ is obtained $r^{2}=0.76$ and $r^{2}=0.70$ for $y / D_{84} \geq 4(N=277)$. Consequently, the logarithmic law achieves a similar fit for the two submergence subsets considered. Similarly, it would be of interest to study whether theoretically valid models for high relative roughness conditions (e.g., 
Aguirre-Pe and Fuentes 1990, Smart et al. 2002) have a greater explanatory power than the logarithmic law.

\section{Conclusions}

The equivalent roughness of gravel-bed rivers, determined assuming a Keulegan-type flow resistance equation, is approximately $2.4 D_{90}, 2.8 D_{84}$, and $6.1 D_{50}$. The values cited are similar to those derived from the literature studied. No correlation was detected between, on one hand, the sediment sorting index and the sediment mobility index and, on the other, the coefficient of proportionality of each grain-size percentile.

\section{Notation}

The following symbols are used in this technical note:

$D_{i}=$ particle size of percentile $i$

$g=$ gravitational acceleration;

$k_{s}=$ equivalent roughness;

$R=$ hydraulic radius;

$S=$ bed slope;

$T=$ free surface width;

$V=$ cross-section mean velocity;

$v *=$ shear velocity;

$y=$ mean flow depth; 
$z_{0}=$ hydraulic roughness of the boundary;

$\alpha_{i}=$ proportionality coefficient corresponding to $D_{i}$;

$\gamma=$ specific weight of water;

$\gamma_{s}=$ specific weight of particle;

$\kappa=$ von Karman coefficient;

$\tau=$ mean shear stress; and

$\tau_{c}=$ critical shear stress.

\section{References}

Ackers, P., and White, W. R. (1973). "Sediment transport: new approach and analysis." J. Hydraul. Div., Am. Soc. Civ. Eng., 99(11), 2041-2060.

Aguirre-Pe, J., and Fuentes, R. (1990). "Resistance to flow in steep rough streams." J. Hydraul. Eng., 116(11), 1374-1386.

Bathurst, J. C. (1982). "Theoretical aspects of flow resistance." Gravel-bed rivers, R. D. Hey, J. C. Bathurst, and C. R. Thorne, eds. Wiley, Chichester, U.K., 82-108.

Bathurst, J. C. (1985). "Flow resistance estimation in mountain rivers." J. Hydraul. Eng., 111(4), 625-643.

Bray, D. I. (1979). "Estimating average velocity in gravel-bed rivers." J. Hydraul. Div., Am. Soc. Civ. Eng., 105(9), 1103-1123. 
Bray, D. I. (1982). "Flow resistance in gravel-bed rivers." Gravel-bed rivers, R.D. Hey, J.C. Bathurst, and C.R. Thorne, eds. Wiley, Chichester, U.K., 109-137.

Charlton, F. G., Brown, P. M., and Benson, R. W. (1978). "The hydraulic geometry of some gravel rivers in Britain." Hydraulics Research Station Rep. No IT 180, Wallingford, U.K.

Colosimo, C., Copertino, V. A., and Veltri, M. (1988). "Friction factor evaluation in gravel-bed rivers." J. Hydraul. Eng., 114(8), 861-876.

Griffiths, G. A. (1981). "Flow resistance in coarse gravel bed rivers." J. Hydraul. Div., Am. Soc. Civ. Eng., 107(7), 899-918.

Hey, R. D. (1979). "Flow resistance in gravel-bed rivers." J. Hydraul. Div., Am. Soc. Civ. Eng., 105(4), 365-379.

Hicks, D. M., and Mason, P. D. (1991). Roughness characteristics of New Zealand rivers. New Zealand Water Resources Survey, DSIR Marine and Freshwater, Wellington, NZ.

Jarrett, R. D. (1984). "Hydraulic of high gradient streams." J. Hydraul. Eng., 110(11), $1519-1539$.

Judd, H. E., and Peterson, D. F. (1969). Hydraulics of large bed elements channels. Report № PRWG 17-6, Utah Water Research Laboratory, Utah State University, Logan, Utah, USA. 
Lee, A. J., and Ferguson, R. I. (2002). "Velocity and flow resistance in step-pool streams." Geomorphology, 46, 59-71.

Leopold, L. B., Wolman, M. G., and Miller, J. P. (1964). Fluvial Processes in Geomorphology. Dover Publications, NY, USA.

Limerinos, J. T. (1970). "Determination of the Manning coefficient from measured bed roughness in natural channels." Water Supply Paper 1898-B, U.S. Geological Survey, Washington D.C., USA.

López, R. (2005). Resistencia al flujo de ríos de montaña: Desarrollo de ecuaciones de predicción. PhD thesis, Univ. of Lleida, Lleida, Spain (in Spanish).

Maresova, I., and Mares, K. (1989). "Flow resistance of channel bed of submountainous rivers." Technical Papers of the Faculty of Civil Engineering, Technical University of Prague, Czechoslovakia, Serie V, 9, 269-305.

Millar, R. G. (1999). "Grain and form resistance in gravel-bed rivers." J. Hydraul. Res., $37(3), 303-312$.

Smart, G. M., Duncan, M. J., and Walsh, J. M. (2002). "Relatively rough flow resistance equations." J. Hydraul. Eng., 128(6), 568-578.

Song, T., Chiew, Y. M., and Chin, C. O. (1998). "Effect of bed-load movement on flow friction factor." J. Hydraul. Eng., 124(2), 165-175. 
Whiting, P. J., and Dietrich, W. E. (1990). "Boundary shear stress and roughness over mobile alluvial beds." J. Hydraul. Eng., 116(12), 1495-1511.

Wolman, M.G. (1955). "The natural channel of Brandywine Creek, Pennsylvania." Geological Survey Professional Paper 271, US Geological Survey, Washington D.C., USA. 
Table 1. Selection of values of coefficient of proportionality $\left(\alpha_{i}\right)$ determined by different researchers into gravel-bed rivers

\begin{tabular}{|c|c|c|c|c|c|c|c|c|}
\hline Reference & $\alpha_{50}$ & $\alpha_{84}$ & $\alpha_{90}$ & $N^{\text {a }}$ & $\begin{array}{c}S \\
(\%) \\
\end{array}$ & $i$ & $\begin{array}{r}D_{i} \\
(\mathrm{~m}) \\
\end{array}$ & $\begin{array}{c}y / D_{i} \\
(\mathrm{~m} / \mathrm{m}) \\
\end{array}$ \\
\hline Bray (1982) & 6.8 & 3.5 & 3.1 & 67 & $0.02-1.5$ & 50 & $0.019-0.145$ & $5-167$ \\
\hline Charlton et al. $(1978)^{\mathrm{b}}$ & - & - & 3.5 & 467 & $0.07-1.4$ & 50 & $0.028-0.113$ & $0.7-80$ \\
\hline Griffiths (1981) & 5.0 & - & - & 186 & . & 50 & - & $1-200$ \\
\hline Hey (1979) & - & 3.5 & - & 92 & - & & - & $0.9-80$ \\
\hline Lee and Ferguson $(2002)^{\mathrm{c}}$ & - & 3.9 & - & 81 & & 84 & - & $0.1-1.5$ \\
\hline Leopold et al. (1964) & - & 3.9 & - & 38 & & 04 & - & $0.5-20$ \\
\hline Limerinos (1970) & 8.2 & 3.2 & - & 50 & $0.07-2.4$ & 84 & $0.02-0.75$ & $0.90-69$ \\
\hline Millar (1999) & 5.9 & 2.9 & - & 176 & - & 50 & - & $4-190$ \\
\hline
\end{tabular}

${ }^{a}$ Number of data.

${ }^{\mathrm{b}}$ Including data taken from channels with vegetation on the banks.

${ }^{c}$ The grain size percentile corresponds to the steps of the step-pool sequences. 
Table 2. Data sources (broken down into references that supplied most data, authors' data, and rest), including some relevant information

\begin{tabular}{|c|c|c|c|c|c|}
\hline Data source & $N^{\text {a }}$ & $\begin{array}{c}S \\
(\%) \\
\end{array}$ & $i$ & $\begin{array}{r}D_{i} \\
(\mathrm{~m}) \\
\end{array}$ & $\begin{array}{c}y / D_{i} \\
(\mathrm{~m} / \mathrm{m}) \\
\end{array}$ \\
\hline Bathurst (1985) & 44 & $0.40-3.7$ & 84 & $0.11-0.74$ & $0.43-11$ \\
\hline Bray (1979) & 67 & $0.02-1.5$ & $84^{\mathrm{b}}$ & $0.03-0.30$ & $2.5-90$ \\
\hline Colosimo et al. (1988) & 43 & $0.26-1.9$ & 84 & $0.04-0.12$ & $2.3-12$ \\
\hline Griffiths (1981) & 136 & $0.01-1.1$ & $84^{c}$ & $0.03-0.69$ & $0.76-120$ \\
\hline Hicks and Mason (1991) & 99 & $0.001-3.9$ & 84 & $0.04-0.80$ & $0.43-26$ \\
\hline Jarrett (1984) & 66 & $0.20-3.4$ & 84 & $0.09-0.79$ & $0.37-11$ \\
\hline Judd and Peterson (1969) & 116 & $0.82-6.6$ & 84 & $0.19-0.92$ & $0.23-3.5$ \\
\hline Limerinos (1970) & 50 & $0.07-2.4$ & 84 & $0.02-0.75$ & $0.90-69$ \\
\hline Maresova and Mares (1989) & 74 & $0.21-1.2$ & 84 & $0.11-0.30$ & $0.60-5.4$ \\
\hline Wolman (1955) & 37 & $0.03-0.35$ & 84 & $0.05-0.14$ & $0.72-17$ \\
\hline Others & 206 & $0.017-16$ & 84 & $0.02-0.78$ & $0.11-93$ \\
\hline Authors' data (López 2005) & $16^{\mathrm{d}}$ & 1.1 & 84 & 0.16 & $0.89-2.2$ \\
\hline Overall & 954 & $0.001-16$ & 84 & $0.02-0.92$ & $0.11-120$ \\
\hline
\end{tabular}

${ }^{a}$ Number of data.

${ }^{\text {b }}$ Obtained only for comparison purposes, through the regression of $D_{50}, D_{65}$, and $D_{90}$.

${ }^{c}$ Obtained only for comparison purposes, applying $D_{84}=2.3 D_{50}$.

${ }^{\mathrm{d}}$ Data obtained in a single reach. 
Table 3. Values of coefficient of proportionality $\left(\alpha_{i}\right), 95 \%$ confidence interval, Mean Standard Error (MSE) and coefficient of determination for regression

\begin{tabular}{cccccc}
\hline & & \multicolumn{2}{c}{ Confidence interval } & & \\
\cline { 3 - 4 }$\alpha_{i}$ & Value & Upper 95\% & Lower 95\% & MSE & $r^{2}$ \\
\hline$\alpha_{50}$ & 6.06 & 6.37 & 5.74 & 1.97 & 0.71 \\
$\alpha_{84}$ & 2.80 & 2.95 & 2.65 & 1.88 & 0.72 \\
$\alpha_{90}$ & 2.44 & 2.60 & 2.29 & 1.87 & 0.72 \\
\hline
\end{tabular}




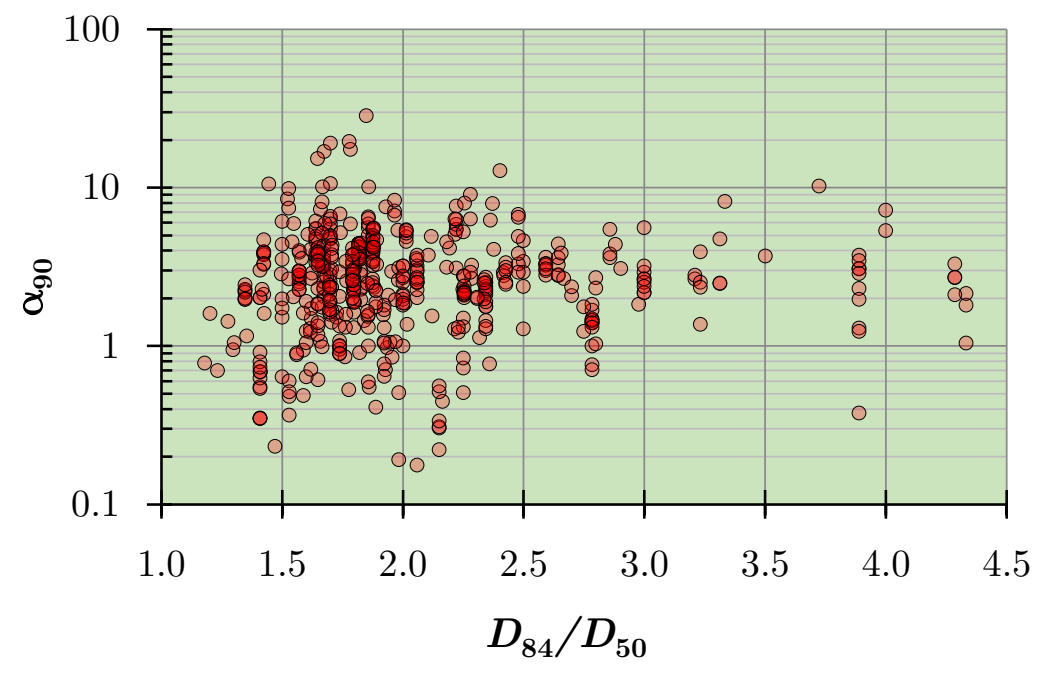

Fig. 1. Relation between $D_{84} / D_{50}$ and $\alpha_{90}$ 